\title{
THE INFORMATIONAL RISK - OPERATIONAL RESEARCH OVER THE NET ACCOUNTING RESULT
}

\author{
Tatiana Dănescu ${ }^{1}$ \\ Mihaela Prozan ${ }^{2}$ \\ Andreea Danescu ${ }^{3}$ \\ Roxana Diana Prozan ${ }^{4}$
}

\begin{abstract}
There is the possibility that the information on which basis the informational risk has been identified and evaluated, not to be correct and impicitly the financial statements not to be in conformity with the represented reality, affecting in this way the objective of the "trustworthy image". On the other hand furnishing some distorted information represents exactly what is the cause of the materialization of the informational risk in the frame of the internal and external decision making processes of the information risk. In order to anticipate, evaluate and adequately control this risk, an important role could be held by the internal control in the entities that furnish information as well as in the entities that have the quality of users of it. In this frame, the carried research has been focused on the analysis of the role and the importance that the internal control could have in the accomplishment of the targeted objectives by the financial statements and in consequence to identify and adequate mechanism for diminishing the informational risk.
\end{abstract}

Key words: informational risk, internal control, the utility of the information, financial statements, trustworthy image, net accounting result

JEL Codes: M41, M42, M48 G28, G38

\section{Introduction}

The materialization of the inherent risks afferent to the operations from the perimeter of the accounting reports or of those that could have an impact in the utility of the accounting information, how is the case of the informational risk, affecting the relevance, the intelligibility and the comparability and/or the credibility of this information, with multiple implications over the targeted users.

In this context, in order to insure the reasonable controlling of the informational asymmetries, the internal and external decision making processes, reclaim the existence in the frame of each entity of a good governance of the way in which the processes and the activities of taking into account the transactions and the operations, as well as of those of communicating the information though the means of the financial statements.

Even though some progresses have bee registered in what concerns the amelioration of the quality of the accounting information, determined by the actions for adequate identifying and finding solutions foe the major problems regarding the production and the use of the information supported by the professional organisms, the legislative authorities, the responsible with the corporate governance and of the management, such that there are a series of risks that imply a broader approach.

1 “Petru Maior" University Tîrgu Mureş, Romania, e-mail: tatiana.danescu@gmail.com.

2 "1Decembrie 1918" University Alba Iulia, Romania, e-mail: Mihaela.Prozan@yahoo.com.

3"1 Decembrie 1918" University Alba Iulia, Romania, e-mail: andreea.danescu@ gmail.com

4 "1Decembrie 1918” University Alba Iulia, Romania, e-mail: roxi.prozan@gmail.com 


\section{Literature Review - internal control, informational riks and the utility fo the accounting information}

The specialty literature, the norms and the provisions regarding the internal control, the internal and external audit, as well as of the accounting ones, treating from different perspectives the complex and dynamic problematic that could affect the utility of the accounting information. The most frequent approach is focused on these instrumenting of the role that the internal control has in the adequate controlling of the inherent risks that could affect the general or specific objectives of an entity or activity.

With time passing, some clarifications have been made concerning the definition and evolution of the concept, the delimitation to other functions or activities, the purpose, objectives, principles, basic characteristics, the coverage, the inherent limits, responsibilities, procedures for the development, implementation and operation of internal control. Relevant in this regard are matters relating to the integration of internal control in the economic entity which is essentially his life (Mikol, 1991), cataloging it as a "means" to achieve its goal (Steinberg, Tanki, 1993), an "element" of a management entity (Dănescu, 2007, p. 216), the "process" which provide assurances regarding the safety and credibility of the financial reporting (Gray, Manson, 2008, p. 253) "a guarantee" to ensure the reliability and comparability of information (Pige, pp. 31-32) etc..

These attributes have highlighted the universality of internal control in relation to its extremely extensive coverage, its relativity given by "the reasonable assurance" provided with regard to the achievement of the objectives pursued (Renard, J. 2002, pp. 122-125, Renard, J. 2010, pp. 140-141), the contributions that it may have on the value of an entity by means of influencing the price of its shares (Kratz, D. 2008), the sustainability of the management forecast (Feng, M., Chan, L., McVay, S. 2009) or the bonds of dependency on the internal control over certain features of the entities, such as length, size, complexity of financial health, etc. (Doyle, J., Ge Weili, McVay, S. 2007) etc..

In addition to clarifying aspects of conceptual nature, wide spaces have been allocated for the identification of appropriate models or frameworks development, deployment and operation of internal control. In this sense, the most relevant ones are the COSO (1992), SNS 55/78 (1990 - SNS 55, 1995 - SNS 78), SAC (1991, revised in 1994), COCO (1995), CobiT, COSO (1996) (2004), Turnbull (1999, revised in 2005), outlined by the ISA model 315 "Identification and evaluation of risks of significant distortion, by understanding the entity and its environment" (2005), the model approved by OMFP No. 946 in 2005, MFP (2005), the model proposed for public administration entities of State revenues (Briciu, S. Dănescu, T. et al. 2009), etc..

Both in the literature (Mikol, 1991; Dănescu, 2007; Caspa, Enselme, 2007; Leitch, 2008), as well as in the rules concerning audit (CAFR, IAASB, 2013, ISA 315) stated that one of the principles governing the internal control or one of the objectives pursued by that provision is "information quality" or "reliability report" (COSO, COCO, COSO, Turnbull, AMF). The principle of informing states that, the information must be verifiable and useful, the features implemented should achieve the objective of "reliability of reporting", which shows that, to be useful information should be: relevant; reliable; available; clear; flexible; verifiable criteria; compliant; neutral; comparable.

Regardless of the perspective or approach, the internal control is inextricably linked to the notion of risk, primarily of inherent risk and/or of the residual one. Also, through other activities such as internal or external audit, the internal control operates with operational risk or of noncompliance, the risk of distortion, the risk of information, etc. (Dănescu, Prozan, Dănescu, 2012, 2013).

In the context of the issues covered, the "informational risk" expresses "... the likelihood that the information on the basis of which the economical risk was expressed, may not be accurate, so that the financial statements to be inaccurate" (Dănescu. T. 2007, pp. 47-51), and therefore it can affect the usefulness of the information presented in these reports. 
As a result, the utility of any information is dependent upon adequate control of risks $t$ any perimeter of action, nature and their typology, in which there are identified a number of factors among which there may be mentioned: the system reliability or the production process, the communication or the reception of information; the existence of a prospective management of risks that are inherent to this system; the development, understanding, implementation and proper application of accounting policies and procedures pertaining to the operations involved; the implementation of an adequate information system, etc..

\section{Research methodology}

Based on the assumptions and the objectives established in the approach of the advanced research, analysing the role and the importance of the internal control in the treatment of risks that may affect the production and communication of relevant information, in particular of the informational ones, in the first place a complete documentation of the literature was carried, as well as of the rules and regulations for accounting, afferent to the internal control and specific to the financial audit.

The proposed research objective was achieved through theoretical and empirical analysis of the role of internal control in the production and communication of accounting information through the financial statements. For this purpose, a constructivist methodology was used, by continuing previous research (Dănescu, Prozan, Dănescu: 2012, Zlin Cehia, WSEAS and IAASAT Conferences; 2012 EMQFB Conferences, Tg. Mureş; 2012, IWAAF Conferences, Alba; 2013 WCBEM Conferences, Antalya) with new approaches to knowledge relating to the investigation of the causes which have led to internal control dysfunction-causes identified in empirical studies carried out-including the ways in which they can be adequately controlled. Thus, on the basis of the information identified in the asymmetries of the information presented in the financial statements and tax returns for a number of economic entities in Romania 9.991- Mureş county, for the financial year 2010 and economic entities 8.250 for the financial year 2011, in this research we focused on defining the relationship between the usefulness of accounting information, information risk and internal control.

\section{Controlling the risks that could affet the accounting information - the results of the empirical study}

From the research carried on how to control the risks that may affect the quality of the information presented in the financial statements, it emerged that there are still a significant number of economic entities from which information on the outcome of the accounting and tax burden presented in the accounting reports and tax returns, are not comparable, in fact these issues have highlighted certain dysfunctions of the internal control.

On the basis of the comparative analysis conducted, a series of non-correlations or nonsyncing between the analyzed information from the materialization of the risk of non-compliance or distortion, have resulted. Synthetic results depending on the correlation or non - correlation regarding the accounting result are reproduced in Table 1. 
Table no.1

The distribution of the entities taking into account the correlation or non-correlation of the information refering to the net accounting result

\begin{tabular}{|l|r|r|r|r|}
\hline \multirow{2}{*}{ NET ACCOUNTING RESULT } & \multicolumn{2}{|c|}{2010} & \multicolumn{2}{c|}{2011} \\
\cline { 2 - 5 } & NO. ENTITIES & \multicolumn{1}{c|}{$\%$} & NO. ENTITIES & \multicolumn{1}{c|}{$\%$} \\
\hline$\bullet$ Correlated information & 7.834 & 78,41 & 6.864 & 83,2 \\
\hline$\bullet$ Non-correlated information & 2.157 & 21,59 & 1.386 & 16,8 \\
\hline TOTAL & 9.991 & 100,00 & 8.250 & 100,00 \\
\hline
\end{tabular}

Source: author's calculation

The results obtained on the bases of the comparative analyses are illustrated in Figure 1.

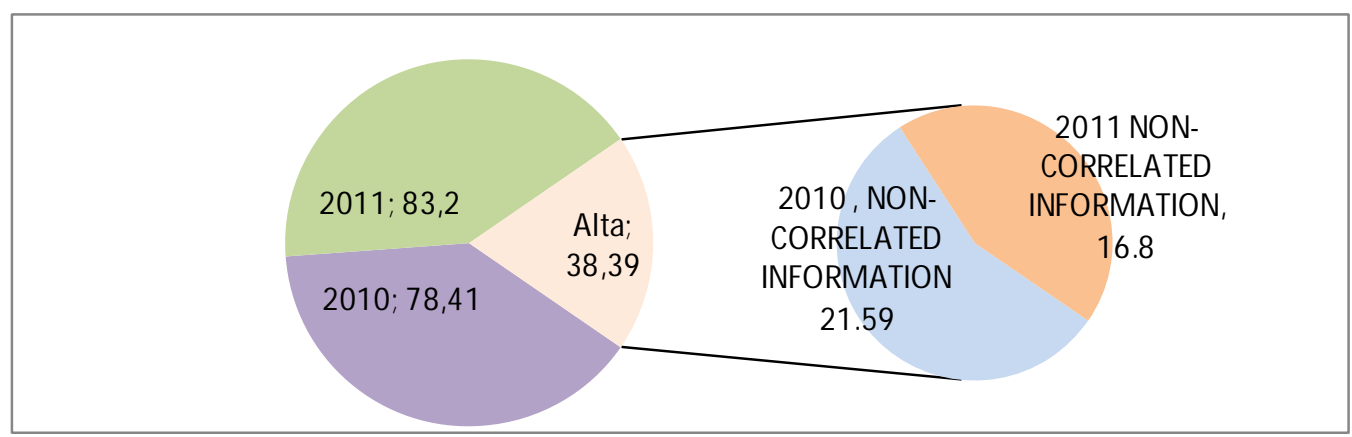

Figure no.1. - The distribution of the analysed taking into account the correlation or noncorrelation of the information referring to the net accounting result

Source: author's calculation

Again, both the hypothesis regarding the relationship of dependence of the usefulness of the accounting information concerning the existence of a proper internal control and as well the mode in which they are drafted, implemented, understood and applied, accounting policies through appropriate procedures have been confirmed. Although we are made aware of the necessity and importance of the internal control, this aspect is not transposed faithfully also in the practice of the economic entities, so the producers or providers of information transmit those "accounting images", which according to reasoning and/or their interests, they want to represent (Dănescu, T., Prozan, M., Dănescu, A.C. 2003, From WCBEM, Antalya, 2013).

From the analysis carried out, it emerged that in 2010 and in 2011, the materialization of the risk of non-compliance or those distortions have led to the emergence of discrepancies between the information analyzed. Internal control dysfunction may highlight that, in addition to affecting the comparability of the information presented in the reports reviewed, another feature of the accounting information was affected, meaning their credibility. According to the national and international framework of accountancy (OMFP 3055, 2009; IASB, IFRS, ISA, 1), in order to be credible, the accounting information must reflect faithfully the representation of transactions and other events, according to the Fund and their economic reality. They also must be neutral and do not contain any significant errors or to be biased.

Alongside these risks, the damage or distortion of the accounting information's credibility may be in turn within the decision-making processes, one of the generators of risk information, indicating the possibility of that risk, the information which has been identified and assessed the economic risk or risk their business may not be correct. Not identifying of such risks can affect the way in which they are being generated as well as the default risk of distortion of the accounting information. For example, in the analyzed situation from the total of the analyzed entities, for 
$21.59 \%$ in 2010 and $16.8 \%$ in 2011 , the information referring to the net accounting result was affected, respectively the information from the financial statements, or the tax returns or even both do not comply with the reality being represented. Note that only significant inaccuracies may affect the usefulness of the information analyzed. Similar reports that analyzed this information may contain other information skewed, which, in turn, by participating in the various decision-making processes, could affect the usefulness of the information arising within them.

Within the entities surveyed, along with the internal control dysfunctions, caused by an inadequate process of risk management, research has highlighted that they are determined by the lack, inadequacy or failure of control mechanisms, risks related to the nature and their typology, the existence of inappropriate accounting policies and procedures, and attitudes and/or deficient perceptions.

Usually, the economic entities are "open organization" that operate in the context of the factors specific to the sectors to which they belong, of those of legal provisions or of those internal or external factors that need a permanent and attentive monitoring. In the absence of some effective mechanisms to control the events generated by the intervening changes, the objective of the "trustworthy image" may be affected by the risks of the business, in which case they can lead to significant distortions of financial statements

Similar to the risk of non-compliance, the business risk is more comprehensive than the risk of distortion, basically it includes both the risk of non-compliance, as well as the one of distortion. In most cases, the business risk has financial consequences and effects on the financial statements, which can have an immediate impact or long-term risks of distortion on the classes of transactions, account balances, and presentations of information at the level of claims or even to the whole of the financial statements. For example, the risk associated with a declining business portfolio of clients can immediately increase the risk of non-compliance or the distortion generated by the poor assessment of the claims in question, and in a situation where it is associated with a period of economic decline the effects will be felt over the long term, and therefore the business risk affects the business continuity of the economic entity in question.

As stated in the research carried out, the risk of distortion is inextricably linked to the risk of non-compliance, as non-insuring compliance with reference standards, leads in most cases to the distortion of information presented in the financial statements, and the cases in which they define the very same events with negative effects on the usefulness of the accounting information. Regardless of the nature and typology of risks which may affect the usefulness of accounting information, in the case in which they are not being controlled adequately, they highlight the existence of dysfunctions of the internal control (Dănescu, T., Prozan, M. 2003, From EMQF, 2013).

If the information that underlyes the business risk is not correct, the informational risk can affect both the risk management process, the non-compliance, and those distortions. The symbolic relationship of causality between the risks identified can be analysed as illustrated in Figure 2.

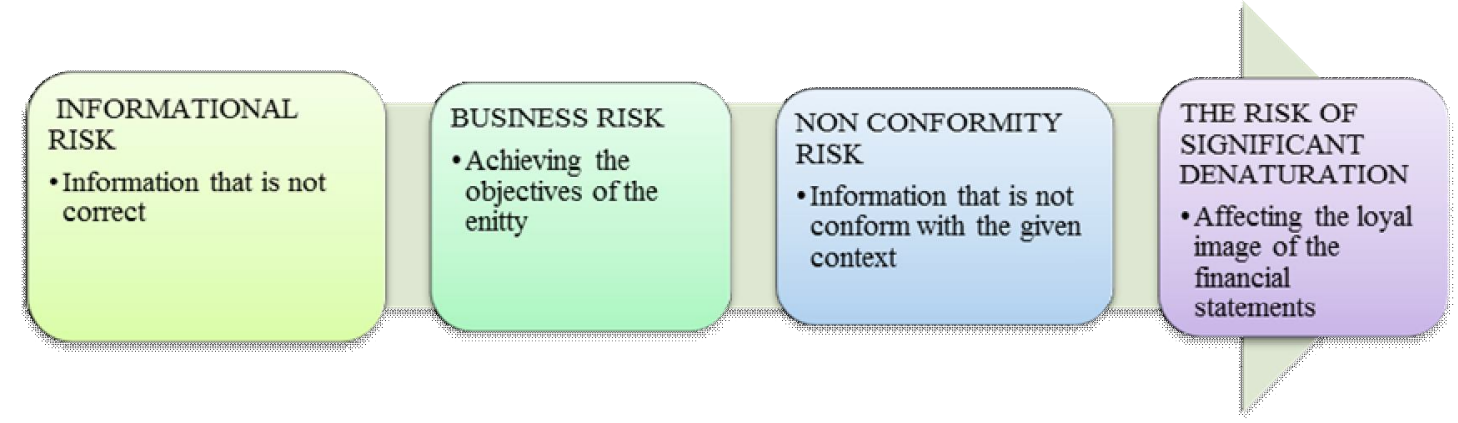

Figure no. 2 . - The relationship between the informational risk, the business risk, the nonconformity risk and that of significant denaturation

Source: The research carried by the authors on the basi of the speialty literature 
In turn, the business risk, the risk of non-compliance or the significant risk of distortion, are factors that generate and supply the informational risk, that can affect the decision-making processes of the internal and external reality. Relevant in this respect may be the information provided by some of the entities that are found in the $21.59 \%$ and the $16,8 \%$ of entities with unrelated information, for which the differences to the reality represented are significant and which in turn can affect the decision making process of the targeted users. Thus, in the context of this research, the information risk refers to the impairment of the usefulness of the accounting information, i.e. their capacity to maintain its qualitative characteristics and/or its security. In this context, the informational risk can be retrieved in a single hypothesis, as the determining factor of the other risks, but at the same time it can be caused precisely the same kinds of risks as those causing them. This relationship is illustrated in Figure 3.

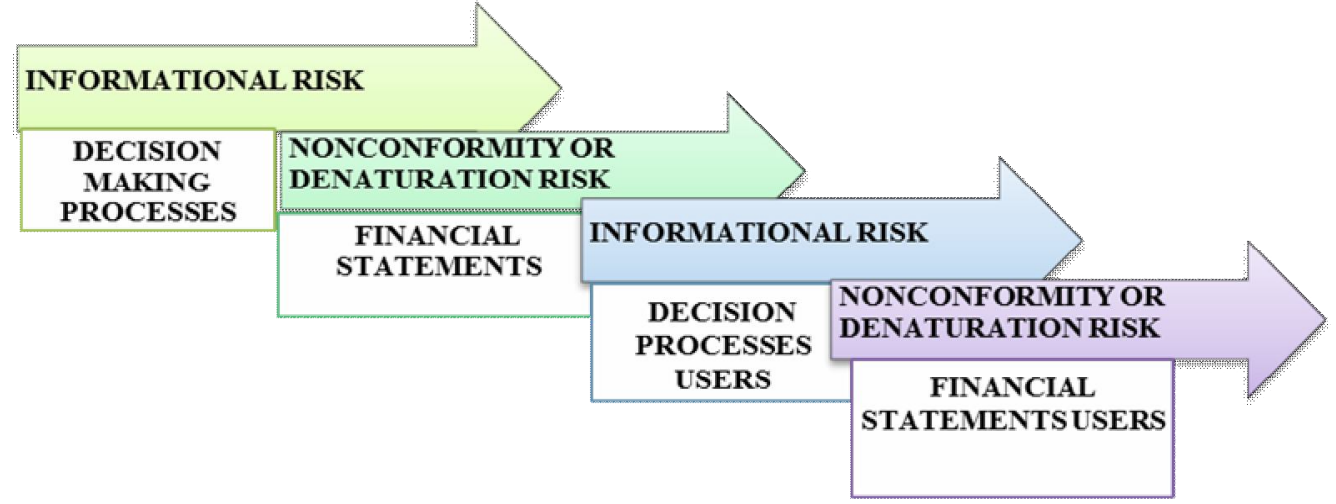

Figure no. 3. - The cause -effect relationship between the informational risk and the risks that could affect the utility of the accounting information

Source: the carried research of the authors based on the specialty literature

Generally, among the factors that determine the informational risk, it is included the large amount of information analyzed and processed, the existence of complex transactions between users and information, the lack of access to the information source, the means of communication, the large number of intermediaries, certain attitudes such as handling or co-editoring of information by the information provider, etc.

These issues require a prospective and proactive management of risks that may affect the quality of the accounting information and the existence of appropriate information systems, both in the entities supplying information, and those who receive them as users of such information. Rather, the proper approach to these risks requires the existence in every entity of a good internal control, which can provide reasonable assurances regarding the permanent information needs of management, as well as other users of the information provided.

The existence of proper internal control mechanisms can contribute to increasing confidence in the information provided through financial statements, while the inadequacy of its internal control is reflected directly in the credibility, relevance and comparability of such information. To achieve these objetives, the entities need models adapted to the specifics and complexity of each entity, to ensure proper implementation of the internal control process, and of the risk management one.

On the basos of the internal control model proposed for the entities that administer the State's revenues (Briciu, S., Dănescu, T. et al. WSEAS, Iaşi, 2011) and on the model developed for the implementation of risk management (Dănescu, T., Prozan, M., Dănescu, A.C., From WSEAS, Severin, 2011), controlling the risks that may affect the usefulness of the accounting information can be represented as shown in Figure 4. 

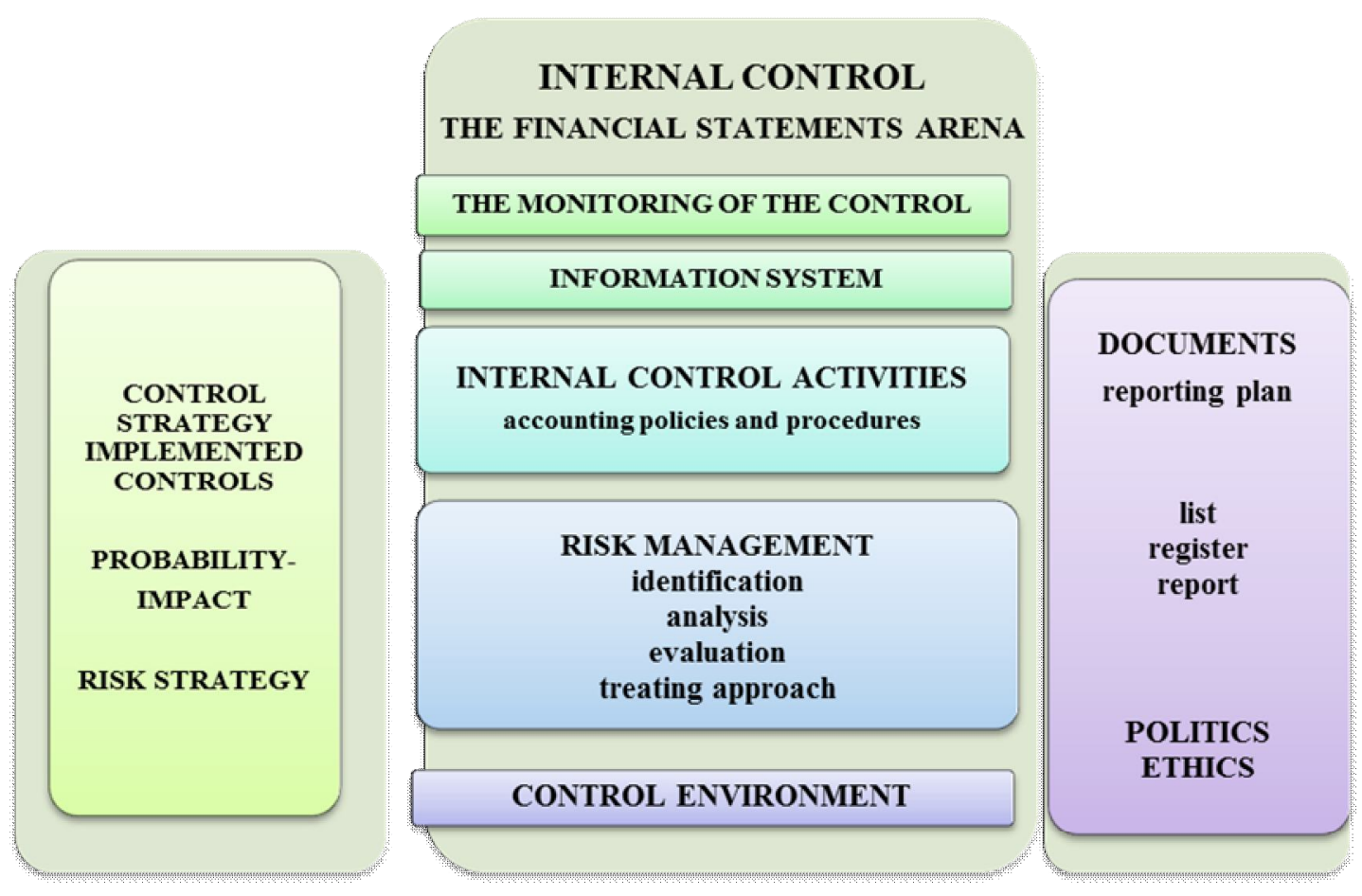

\section{Figure no. 4. - The process of controlling the risks that could affect the utility of the accounting information \\ Source: the carried research of the authors based on the specialty literature}

In the context of the aspects covered by an adequate approach towards the informational risk, the business transactions, defects or distortions that may affect the usefulness of accounting information requests the implementation and the consistent operation of each component of internal control, as well as to its whole.

The existence of a proper control environment, through which a clear policy on the treatment of risks may be established that may affect the usefulness of financial statements, the identification, analysis, assessment and appropriate treatment of these events, the implementation of internal control activities to respond effectively in relation to their nature and their typology, on the basis of the reliable information provided by an efficient information system, as well as the monitoring and periodic re-evaluation of the performance of process are just a few of the most relevant aspects that can ensure the success of this approach.

Although thorugh the "reasonable assurance", the internal control cannot provide absolute assurances concerning the usefulness of the accounting information,still if it is appropriate it can stimulate, influence and improve the quality of the financial statements under the appropriate mechanisms for entities managing the risks involved.

What is important is that each of the actions and operations carried out shall be formalized by means of the appropriate documents, so that to contribute through the capitalization of knowledge and the facilittion of the learning process to create a strong organizational culture based on responsibility. It is also necessary to identify the risk factors in a highly dinamic environment, the definition of appropriate risk strategies according to the nature and typology of the identifie risks, and their basis to determine the most appropriate mechanisms to ensure effective implementation of internal control activities.

An important role in controlling the informational risk and other risks in the financial statements of the internal and external auditors, which depending on the objectives pursued and the 
powers they have, can help to improve internal control and the credibility of the financial statements, thus ensuring safety within the decision-making processes of users of information.

\section{Conclusions}

In a constantly changing environment, which is influenced by the trends of internationalization and globalization of the economies, the new information technologies, marked deeply by the financial pressures arising from the current economic and financial crisis, the usefulness of the information is affected by new risks and new risk factors that are difficult to anticipate, identify, analyze, quantify and control.

The dysfunctions of the internal control of the economic entities for which the information in the financial statements analyzed are not related or are not in conformity with the situation represented, have highlighted that the usefulness of the information is affected by a number of risks or risk factors, internal and external, which manifests itself both in the arena of such situations, as well as in other activities, processes or operations carried out by the entities concerned.

Taking into account the cognitive valences attributed to these concepts, these risks could have diverse approaches. Apparently, by using the concepts of "informational risk" "business risk", "risk of non-compliance" or "risk of distortion" it coud be said that they define completely different issues, but if one examines their content carefully, it becomes evident that essentially they can be determined by the same factors, they have some similar characteristics and consequences, even more there could be some causal relationships or inclusion. In this context, there are situations in which the risk information, determines the risk of the business, which in turn can retrieve or generate the risk of non-compliance or of significant distortion.

A touch of non-compliance of the accounting information of the usefulness of financial statements is determined by the materialisation of the risk, which in turn may be the determining factor of the informational risk in the decision-making processes at which this information is part of, and as a consequence both reports providing such information are denaturated.

The knowledge and the proper application of the concepts in practice requires an open attitude and proper training of those involved in the process of internal control and/or at risk management. Also, an adequate internal control as a determinant of a good corporate governance, can be achieved only on the basis of models adapted to the specifics, the size and complexity of each entity. Therefore, in relation to the nature and typology of risks which may affect the usefulness of accounting information will be identified/elaborated and implemented those mechanisms which ensure the proactive and forward-looking management of such events.

An important role in improving the reliability of the information in the financial statements of the internal and external auditors, which according to powers conferred by law, by the findings, opinions and recommendations to help increase the performance of internal control and to improve the usefulness of the information. Also, in order to improve the quality of accounting information is required by the active involvement of all stakeholders-regulatory authorities, professional bodies, managers, people in charge of the corporate governance, investors and other interested parties to create a regulatory framework that facilitates proper management of all risks that may affect the usefulness of this information.

Given the complexity of the researched topic, on the basis of the obtained results we intend to continue the researach on new approaches reagrdign the adequate control of risks that could affect the utility of the accountinng information. 


\section{References}

1. Bernard F., Gavaraud R., Rousseau L., 2010. Controlle interne: Concepts, Aspect reglementaires, Gestion des risques, Guide d'audit de la fraude, Mise en place $d$ un dispositiv de controle permanent, Référentiels, questionnares, bonnespratiquess, Paris, Editions Maxima

2. Briciu, S., Dănescu, T., Prozan, M., Dănescu, A.C. A Model Of Internal Control Applicable To The Administration Activity Of State Revenues, WSEAS Multi-conference on Applied Economics, Business and Development (AEBD), Books Proceedings, WSEAS E-Library, Iasi, Romania, 1-3 iulie, 2011

3. Caspa B., Enselme G.., 2007. Manuel de comptabilite approfondie, DCG Epreuve, Edition X, Paris, pp. 62-63.

4. Dănescu T., 2007. "Financial audit - convergences between theory and practice", Publishing House Irecson, pp.47-51 and pp.216.

5. Dănescu T., Prozan M., Dănescu A., 2013. Accounting policies and procedures - theoretical and practical connotations in treating risks, Procedia Social and Behavioural Sciences Journal, Vol. 67, World Conference on Business, Economics and Management 2013 (WCBEM), Antalya

6. Dănescu T., Prozan M., Dănescu A., 2013. Non-conformity risks - theoretical and practical conotations, Conference on Emerging Markets Queries in Finance and Business (EMQFB), Tg Mures, 24-27 octombrie 2013, published in Procedia Economics and Finance.

7. Dănescu T., Prozan M., Dănescu A. 2012. The utility of the internal control in insuring the conformity between the accounting and fiscal reporting of the Romanian entities, The 1st WSEAS International Conference on Finance, Accounting and Auditing (FAA), Books Proceedings, WSEAS E-Library, Tomas Bata University, Zlin, Czech Republic, 20-22 septembrie, pp. 305- 311.

8. Dănescu T., Prozan M., Dănescu A., 2012. The accounting policies and procedures delimitations and interferences, Annales Universitatis Apulensis, series Oeconomica Alba Iulia, 14 (2), pp. 357-368.

9. Dănescu T., Prozan M., Dănescu A. 2012. The role of the risk management and of the activities of internal control in supplying useful information through the accounting and fiscal reports, Conference on Emerging Markets Queries in Finance and Business (EMQFB), Tg Mures.

10. Dănescu, T., Prozan, M., Dănescu, A., 2011. The Risk Management Model for Insuring a Good Corporate Governance, 1st International Conference on Tourism and Economic Development (TED), Books Proceedings, WSEAS E-Library, Drobeta Turnu Severin, Romania, 27-29 octombrie.

11. Doyle J., Ge Weili, McVay S., 2007. Determinants of weaknesses in internal control over financial reporting, Journal of Accounting and Economics,

12. Feng M., Chan L., McVay S. 2009.Internal Control and Management Guidance, Journal of Accounting and Economics.

13. Gray I., Manson S., 2008. The Audit Process: Principles, Practice and Cases, Londra, Editura Thomson.

14. Kratz M., 2008. Causes and Effects of Internal Control Outcomes, Maastricht University Library,

15. Mikol A. 1991. Principes genereaux du controle intern, Revue Francaise de Comptabilite nr. 219, p.72.

16. Steinberg R. M., Tanki F. J., 1993. Internal Control - Integrated Framework: A Landmark Study, The CPA Journal, Vol. 63, No. 6, p 1-5, pp. 16-20. 
17. Pige B. 2011. Qualite de l audit, Enjeux de l audit interne et externe pour la guvernance des organisations, Groupe De Boek, Bruxelles, pp. 31-320.

18. Renard J., 2002. Theorie et pratique de l'audit interne, Editions d Organisation, Paris, France, translated in Romanian as Teoria şi practica auditului intern (IV ed.), edited by Public Finance Ministry, 2003, pp.122-125.

19. Renard J., 2010. Theorie et pratique de l audit interne (VII ed.), Eyrolle, Paris, Editions d Organisation, pp.140 - 141.

20. Tabără N., Briciu S., 2012. Current issues and perspectives in accounting and management, Iaşi, Editura Tipo Moldova, pp.209-210.

21. http://www.coso.org/documents/coso_framework_body_v6.pdf, Internal Control Integrated Framework, 2011, COSO - The Committee of Sponsoring Organizations of the Treadway Commission, SUA.

22. http://www.aicpa.org/RESEARCH/STANDARDS/AUDITATTEST/ASB/Pages/AuditingSta ndardsBoard.aspx, SNS 55/78 - AICPA - Consideration of the Internal Control Structure in a Financial Statement Audit.

23. http://www.audit-is.com/terminology/SAC-termDefinition.htm, SAC-Systems Auditability and Control -Institute of Internal Auditors Research Foundation IIARF.

24. www.ifac.org/.../internal-controls-a-revie.pdf, Internal Controls-A Review of Current Developments, 2006. COCO -Criteria Of Control Framework.

25. https://www.isaca.org, CobiT - Control Objectives for Information and Related Technology IT Governance Committee (ITGC), Information Systems Audit and Control Association (ISACA).

26. www.coso.org/.../coso erm executivesummary, COSO II, Committee of Sponsoring Organizations of the Treadway Commission, Enterprise Risk Management - Integrated Framework Executive Summary.

27. www.icaew.com/en/library/.../turnbull-report, Turnbull Report - Institute of Chartered Accountants în England and Wales - (ICAEW).

28. IAASB, 2012. Handbook of International Legal Provisions regarding Quality Control, Audit, Revision, other Insurance Services, vol. I, translated by CAFR, Bucharest, 2013. 315 International Audit Standard „Identifying and evaluating the risk of significant denaturation by understanding the entity and its environment".

29. IASB, 2009. International Standards of Financial Reporting (translation), Ed. CECCAR, Bucureşti, 2009.

30. The order of the public finance, ministre nr. 946/2005 regarding the internal control Code, Romanian Official Monitor 675/2005.

31. The order of the minister of public finances nr. 3055 from 29 October 2009 for the approval of accounting situations in conformity with the European directives, Official Monitor 766/2009.

32. www.amf-france.org, AMF - L'Autorité des Marchés Financiers, France. 